\title{
Management of the National System of Sharing Knowledge Using the Example of the SYNAT Project
}

\author{
(Using BI Tools and Realization of Open Access Conception) \\ Jerzy Kisielnicki and Anna Maria Misiak \\ Warsaw University, Warsaw, Poland \\ jerzy@kisielnicki.edu.pl aniamisiak1@gmail.com
}

\begin{abstract}
In this article we would like to present the significance and problems related to the realization of projects for creating a national dissemination system. It is recommended to use BI systems including the management dashboard to manage the project of building and using the system. Created in Poland, SYNAT system aims at disseminating scientific and technical information to vast audience both in Poland and abroad. The article is also concerned with issues connected with using the Open Access concept. We believe that accepting this concept is a necessary condition in building such system. The article analyses BI solutions which seem to be the most suitable for use in such projects. Using the evaluations of experts a comparative analysis of solutions in commercial use was also carried out. The results of the analysis show that it is difficult to provide a clear answer regarding the usefulness of the analyzed tools. Nevertheless, four systems were chosen: SAP Business Objects Enterprise XI, Microsoft BI tools (integrated BI offering), Oracle Enterprise BI Server, QlikView, which should undergo more detailed analysis depending on the conditions of a given project.

Both authors of the article participate in the SYNAT project. Jerzy Kisielnicki has been responsible for the recommendation of the project management tool and Anna Maria Misiak has carried out the tool research and evaluation highlighting the most adequate solutions for project usage.
\end{abstract}

Keywords: SYNAT, National Information Systems, project management, content management, Systems of Education, information society, knowledge management

\section{The Need of Realizing the SYNAT Project}

The main aim of this article is to present a proposal for using BI class systems, especially the tools they include, i.e., the management dashboard, to manage dissemination of scientific and

Material published as part of this publication, either on-line or in print, is copyrighted by the Informing Science Institute. Permission to make digital or paper copy of part or all of these works for personal or classroom use is granted without fee provided that the copies are not made or distributed for profit or commercial advantage AND that copies 1) bear this notice in full and 2) give the full citation on the first page. It is permissible to abstract these works so long as credit is given. To copy in all other cases or to republish or to post on a server or to redistribute to lists requires specific permission and payment of a fee. Contact Publisher@InformingScience.org to request redistribution permission. technical information to a wide group of users. The article also covers the problem of using Open Access conception as a necessary condition to build such a system. The article would also like to present the significance and realization issues related to the project, the aim of which is to disseminate knowledge on a national scale. Open Access provides free and unlimited access to scientific publications through the Internet. In 
many developing countries the idea of Open Access is just being examined both in academic circles and appropriate government institutions responsible both for the development and funding of the sciences. Despite the fact that the projects focus is Poland, many other countries are in a similar situation, for example Slovakia, Kazakhstan and Ukraine. The lack of the internet access to many Polish scientific dissertations hinders building a knowledge-based society in Poland and widens the gap in Polish sciences and higher education. Further development of science in Poland is not possible without a national infrastructure (a catalogue with scientific publications, on-line libraries and repositories) allowing simple and uniform mechanisms of publishing, searching and obtaining publications. Therefore, a strategic project with the working name SYNAT (Science and Technology System) is currently being realized in Poland. 16 scientific units at the most of leading national universities are working on creating the system. The aim of the project is to create a concept and implementation of on-line hosting and communication platform for digitalized knowledge used by researchers, research units, students etc. The research element is part of the Strategic Program of the National Centre for Research and Development known as the Interdisciplinary System of Interactive Scientific and Technical Information. The project is funded by the National Center for Research and Development. The idea of Open Access has developed as a social movement based on the concept of knowledge and culture as a common resource and on the models providing free access to the content.

The initiative of open science is to provide the access to the results of scientific research and publications is an obligation for a scientist and generally speaking it provides equal opportunities to participate in a knowledge-based society. The Open Access idea endeavors to realize various projects promoting models of open scientific communication (especially using digital media), open (meaning free of charge from the user's point of view) access to scientific journals and open educational resources at academic levels. Supporting development of these models is necessary to ensure competitive power for science, develop innovative potential and equal educational possibilities for people deprived of the access to large research centers. The social movement of open science is based on the following foundations:

- liberalization of the access to knowledge seen as a common property,

- generating a society of virtual scientists focused around open distribution of the research results,

- openness, clarity and widening the results of scientific achievements,

- quickly developing communication processes in science as a result of developments in teleinformatic technologies,

- understanding publications as a part of research progress and not as a finished product.

\section{Open Access Conception as a Method of Disseminating Knowledge and Its Role in the SYNAT Project}

Access to the achievements of international science and technology is very important for the scientific and economic progress of a country. Therefore, the aim of the completed SYNAT project as one of many projects realized in the contemporary world is creating a universal, open, repositories archival hosting and communication platform for on-line resources for science, education, and open knowledge-based society. The proposed realization covers a wide scope of research tasks subordinate to the main goal: creating a comprehensive national system connected to systems in other countries. The system should include: 
- A computer platform realizing all functions of the system,

- application sub-systems allowing the platform to service a wide scope of content resources ensuring high scalability level and inter-operational function in an international setting,

- generic sub-systems allowing integration of new classes of future applications,

- $\quad$ sub-system for new communication models for scientists and open knowledge based societies including a program of sharing and promotion for a whole society,

- set of proposed legal models allowing the further of open communication models in science, education and cultural heritage area,

- operational model ensuring the endurance of the system and raising questions of possible areas for its commercialization.

The SYNAT project is an attempt to disseminate knowledge on an Open Access base. Open Access, "OA" means free, universal, stable and immediate access for each user to digital forms of data, scientific and educational content. The notion is closely connected with the scientific Open Access Movement, which has been developing since 1990 and has been acting to build new models for open scientific communication. The main communication channels which allow the sharing of knowledge in this model is open journals and open repositories.

In all international solutions sharing of scientific information is done using a combination of options offered by IT and techniques for absorbing written text created over centuries. Hypertexts solutions and communication protocols (standards) allow varied operations on resources of searched units - such as combining, eliminating, managing metadata, as well as creating lists. Library catalogues may be merged in one base, searched commonly with other databases in libraries all over the world. It is not only about the issue of stimuli to innovate. The area of distribution of knowledge and its contribution to general well-being should be also taken into consideration. It is significant that in the case of digital resources there is no competition in using them because infinite copies can be created. It is both an opportunity (anyone fulfilling given conditions can use the data) and a threat (plagiarism and copyright risks). When building a system for providing scientific and technical information one must be aware of the existing legal restrictions in the area. The designers of the SYNAT platform are aware of these restrictions.

The American doctrine 'fair use', which leaves it to a decision of the court if in a specific situation where copyright is violated, is more flexible than continental European copyrights. However, the later copyrights include a list of works with exceptions and exemptions from legal protection; it is quite strict and very hard to be modified. It is also not identical in all member states of the European Union. The doctrine fair use facilitated concluding the agreement between Google and the organization of collective management of copyrights in the USA.

The economic analysis of copyrights has recently become aware that they cannot further develop on the basis of the principle of ,one-size-fit-all-approach”. The fair use principle allowed Google to conclude the agreement regarding digitalization of works which includes ultimately very wide ranges of works including contemporary authors, unknown authors and such authors the identification of which in the given time range turns out to be impossible (Orphan works).

Google's initiative has raised legal issues. Google constantly implements new services raising objections due to the scale of the Internet and market position of the company (app. $90 \%$ share in the search engine market). An example is Google News, which searches media websites and collects the most interesting news, meaning most often read by Internet users. Google publishes titles and short fragments of texts with links to source articles. 
Press publishers mostly protest because many people read only fragments of works and do not read whole texts. This recalls the recent discussion regarding online press reviews realized on individual orders and contradicting judgments in different countries regarding the issue of whether such companies should pay publishers. In the center of the debate is also the Google Books project, which aims at creating a digital library of all the books in the world. Publishers are afraid of the collapse of the printed book market and an actual Google monopoly in the digital access market and therefore dictating financial conditions. As a result, a private company would have control over all the intellectual achievements of mankind. Google also offers additional services thanks to which it obtains so called sensitive information - private information about Internet users.

Yahoo, competition to Google, initiated the project - Open Content Alliance (OCA). The world's libraries are divided, deciding to work either with Google or OCA. They have different method of work. Google pays libraries to scan books, while OCA demands that its customers scan them themselves. First these books are scanned, the copyrights of which have been distinguished and transferred to the public domain. The discussion continues on how to optimally interest authors financially (e.g. through incomes from advertisements) and motivate them to allow a free access to their works.

In the legal system some norms can highlighted which hinder or facilitate achieving the Open Access idea. According to W. Szpringer the regulations hindering Open Access include:

- copyrights seen as a manifestation of "moral rights" of an author which allow something, prohibit something or forces potential partners into something without asking what their intention are because the legislator knows better (e.g. the issue of derivative works),

- patent rights which do not allow the publishing of results from research before filing patent applications because it will lose the patentability (problem for new products),

- ancillary rights restricting the rights of third parties which also restrict usage of the content on Open Access platforms (e.g. audiovisual works),

- legal framework protecting intellectual rights of unknown authors (orphan works).

The regulations friendly towards the Open Access idea include:

- regulations allowing realization of contracts and licenses within basic legal rules by the court system; it is sufficient to convince an author to share their work on the basis of Open Access rule within the green path.

- rights guarantying priority of personal rights of an author (the requirement of defining the name and surname of an author),

- rights guarantying authenticity of a work (ensuring integrity of a work),

- regulations ensuring transparency i.e. comprehensive information and consumer protection.

It should be stressed that the possibility to realize the access on the basis of the Open Access principle within the green path requires concentration and providence of an author while signing a contract with a commercial publisher. Only when an author does not delegate these rights to the publisher, the author may freely decide regarding this matter. In the German system recent changes in copyright law help authors in this regards. The legislator made amendments to the Copyrights Act (Urherbergesetz) which states that even if an author has delegated the copyrights to a publisher, after a year they automatically revert back to the author. The process of managing scientific and technical information combines elements of obtaining, creating and transferring it into information available to the public. 
The transformation period promotes innovation. The pressure on innovation results from new opportunities in entrepreneurship, strong competition and requires a favorable institutional environment. The role in the development of Poland which is assigned to the issue of information and knowledge shows the realization of the above mentioned project devoted to interdisciplinary system of interactive scientific and technical information SYNAT (Scientific and Technical Information System).

The main task of SYNAT is to create a system of exchanging scientific and technical information in Poland. What are the relations between KSINT (National Scientific and Technical Information System) and SYNAT can be the core of KSINT. Regarding SYNAT, we know its scope, who realizes it and what resources are devoted to realizing it. Obviously, some elements of national scientific and technical information system are in operation, for example, scientific and public libraries, networks of universities and research institutions. Is it a coherent system, though? It may raise some doubts. A national system which SINTO (domestic network of scientific and technical information) is supposed to be in the target layer should provide the users with an efficient tool to make deliberate actions both in the area of scientific policy and its applications. The result of it should be an increase in the scientific quality of our works and modernization of the Polish economy. SYNAT is supposed to be a common IT platform catalyzing all assumption of SINTO. To evaluate the level of Polish publications we may use the Impact Factor (IF). This factor allows defining prestige and impact of the scientific journals where Polish scientists publish. The problem of Polish science' position is only mentioned here and is not a subject for this article, similar to the analysis of the impact of science on the economic development of Poland. We may also define such target scientific and technical information system as a multilevel structure. This system allows its users to transform information regarding scientific and technical progress into desired output information using proper procedures and models. Obtaining this information results both in scientific and economic decisions.

We may define SYNAT as a subsystem of the national information system, which includes: an organized set of people (creators and their co-workers), processing procedures, databases, models, knowledge and devices used to provide scientific information and its application for all those interested in the topic. The national system of scientific and technical information is a complex labyrinth of scientific and technical information systems gathering information and disseminating this information to domestic users and within defined range also to users abroad. Therefore, it is an integrated complex of scientific and technical information systems, including all national systems and connected with them international systems and systems managed by foreign entities. Therefore, the construction of SYNAT requires coordination and standardization of the elements listed above the aim of which is to ensure coherence of the system. IT tools such as BI are helpful in here.

\section{BI as a Tool Managing Systems Disseminating Knowledge}

The genesis of Business Intelligence is said to be the year 1966. At that time with an academic grant James H. Goodnight, John Sall, Jane Helwig and Tony Barr created a system to carry out statistical analyses on an IBM platform. Since then large concerns producing software for business started to rapidly develop analytical tools. In 1972 SAP was established by former employees of IBM. In 1975 Nie and Hull established SPSS Inc., and in Albuquerque (New Mexico, USA) Bill Gates and Paul Allen established Microsoft. Shortly afterwards SAS Institute Inc., Software Development Laboratories was established when IBM did not use the model made by Edgar Frank Codd (creator of referential databases and OLAP notion) - transformed later into Oracle, Hyperion, and in 1982 into Cognos, (Rawicz-Mańskowski G. (2008), Business Intelligence - from where to where?). 
Currently BI is seen as a tool directed at top management as well as operational management and transitional activities in an organization.

For the last 10 years it has been noticed that projects are more and more significant in organizations. Wide technological possibilities contribute to the necessity of constant improvements, fulfilling expectations of customers. This raises new challenges for companies, which are realized through a number of changes, mergers and take-overs. In order to carry out such actions swiftly, organization start projects by assigning responsible people for realization of the tasks in order to achieve the defined changes (implementation of a new system, integration with an incorporated company etc.). Therefore, the notion of a project or a program becomes common, moreover it becomes a part of an organization in a matrix approach, an entity with changing themes and responsibilities. A vast number of carried out programs and projects often within one organization resulted in BI suppliers adjusting their offers to the needs of the market. Such IT concerns as SAP, Microsoft and other already offer tools dedicated to project management. More and more often BI becomes necessary to coordinate actions, integrate data coming from various sources, report actions and deliverables in a project.

A project, similarly to an enterprise has a strategy, organizational structure and business processes (resulting from themes and methods of project management) with assigned owners, which are realized in a specified time. Each project management method (PRINCE 2, PMI etc.) includes monitoring and controlling the project. Usually it is realized by a number of reports, meeting with a project team and steering committees. Products of such monitoring may be also dashboards created manually in a form of compressed reports or page-long weekly updates of the main parameters. Data for such dashboards are usually collected manually from the team members or collected manually from different files stored on a common project disk. It is a proven method which is necessary for the success of a project. This method is sufficient to realize small and medium sized projects.

The situation is different in the case of vast projects in which many state, academic and other institutions are involved. SYNAT is an example of such a project. Then manual preparation of a dashboard is difficult because it requires collecting large quantities of data from many sources and participants in the project which is connected to the risk of collecting incomplete data or the lack of data. This may blur the actual progress of works within the project. Therefore, more and more often it is proposed to use a management dashboard which in an intelligent way will include up-to-date knowledge regarding realization and evaluation of the project.

Coordination of a decentralized and complex structure where the theme of the project engages many different users and the management structure is supposed to have a decentralized frame will require proper monitoring and evaluation of works. Therefore, BI made properly available to individual coordinators of the SYNAT project seems to be the right solution.

The most important areas of monitoring the SYNAT project, which at the same time may be provided by a BI solution, will be:

- budget (project expenses)

- legal decisions, rules of participation and financing individual participants of the project (resources control)

- project deliverables (their value for the project and their quality)

- realization time of tasks including delivering products

- issues and risks including appearing problems requiring escalation.

Budget seems to be the simplest element to control because it is easily measurable and until the platform is launched it will concern only expenses. Nevertheless, for its proper evaluation it will 
be necessary to define the conditions required for the information which will be shown in the dashboard:

1) possibility to integrate it with the financial and accounting system.

2) preparing a structure of cost centers - in order to control costs and assess expenses depending on the department where they are created it is worth to define a hierarchy of cost centers which will be assigned to each accounting document.

\section{Legal decisions and rules of participating and financing individual participants of the pro-} ject are one of the elements which should be registered in a HR and payroll system or another system which will fulfill a similar function. Regardless of the remunerated methods used, HR information such as $\mathrm{CV}$, contracts with persons and legal entities should be kept in electronic versions in a properly protected system. BI offers the possibility of virtual work space for participant which is described further this dissertation, restricted for use of a narrow group of SYNAT coordinators.

Project deliverables (their value for the project and quality) are an area which has to be monitored. However, in order to achieve it, it is necessary to implement a few organizational rules as well as tools to use BI functionality:

1) A virtual workspace for participants. Preferably it should be a dedicated application for virtual work where participants have the possibility to work on documents on-line, or at least they can save their works in a dedicated virtual area. Such a system should ensure registering work time and the name of the user who works in it. Other work conditions of such application are:

a. The method of categorizing documents by adding attributes to them (such solutions are offered exclusively by BI). It is based on saving documents in a set localization in an orderly way. Thanks to this the documents can be viewed and searched in various perspectives. It will ensure the possibility of quick access to information on the products for the needs of the dashboard.

b. A possibility to define work-flow for a given product. In an operation like SYNAT products will be the result of the work of more than one person. They will be also approved by the succeeding levels of hierarchy. Thanks to the work-flow system, it will be possible to quickly identify at which level of approval is a given product or whether it has already gone through the content, quality and other approvals.

c. Versioning of documents. It is necessary to avoid saving versions with manual names' changes. Documents should be stored under one name. The system should save in the background following previous versions of the documents, giving the possibility to return to the previous versions at user's request.

d. Advanced management of the access to the chosen products / documents / system areas. Individual users should have access only to chosen product libraries. The system should ensure such possibilities including the option of read only files. With such a vast project and so many participants it can be dangerous to make everything available to everybody. Therefore, a system which would be only a file server with created folders may complicate managing the access.

Time of task realization (including providing products) and assigning deadlines for delivering tasks should be registered in a centralized location. With decentralized structure of project coordination usually coordinators create their own sub-planes in their own format. In order to maintain coherent knowledge regarding the progress of works, it is necessary to implement a central tool allowing the recording of tasks available on-line. It would be best if that tool is a functionality of the points described above as a virtual workspace for the participants in the project. Then 
recorded tasks may be integrated with the recorded products, time of their delivery, and therefore automatic task up-dating. In case of central registering of the realization of tasks it is necessary to appropriately train users, especially coordinators of the individual areas of SYNAT. They should know in what way the project is realized regarding recording the realization of tasks, how to use tools and what the consequences of not using it are.

Similar functionality offered by the tool for virtual work and organization is required to register issues and risks in the project. Issues and risks are not measurable elements. Nevertheless, it is possible to register them centrally by assigning coherent characteristics e.g. the importance of the problem, influence on delivering the project etc. Their description will depend on coordinators and leaders. Thanks to uniform registration and the same level of knowledge on how to register them it would be possible to send it to the dashboard and monitor appearing problems in the project which require immediate reaction.

Properly chosen BI tools may facilitate and speed up the implementation of the platform of OPEN ACCESS conception.

\section{Choosing BI Solution}

The market of IT tools offers a range of Business Intelligence type solutions. Some assumptions have been made in this dissertation to choose and compare the products which could fulfill as far as possible the requirements of the SYNAT projects.

- Building own tool vs. buying tool out-of-the-box.

One of the first assumptions made for the needs of this work will be considering the tools available on the market. SYNAT operation is a consortium of many institutions. Building a tool allowing reporting is an investment (requiring identification of needs, decisiveness, software etc.) which is rather expensive and lasts too long for the needs of a project, which should end at a specified time. Currently available tools offer very advanced functionality out-of-the-box. There is no need to start a 'big project' for the needs of project management.

- Open-source tool vs. licensed tool

The next assumption is to compare available licensed tools. There are many open-source tools available. However, they still offer low quality regarding functionality or efficiency. The SYNAT project requires the cooperation of a large group of participants, quick infallible tools which will be supported by their suppliers. The use of freeware should be avoided because as it is shown in many statistics the cost of using such software may be higher than buying proved licensed tool.

According to the Dutch consulting company, Passionned Group (Passionned Group (2012). Business Intelligence Tools Survey 2012. Retrieved from http://businessintelligencetoolbox.com) the list of BI tools with the highest number of functions of BI tools offered currently by producers are:

Table 1: List of the biggest BI solutions

\begin{tabular}{|l|c|l|}
\hline \multicolumn{1}{|c|}{ Business Intelligence Tool } & $\begin{array}{c}\text { Most recent } \\
\text { version }\end{array}$ & \multicolumn{1}{|c|}{ Supplier } \\
\hline Oracle Enterprise BI Server & $11 \mathrm{~g} 1$ & Oracle \\
\hline SAP Business Objects Enterprise XI & $\mathrm{r} 4$ & SAP \\
\hline Microsoft BI tools (integrated BI offering*) & $2008 / 2010$ & Microsoft \\
\hline SAS Enterprise BI Server & 9.2 & SAS Institute \\
\hline Microstrategy & 9 & Microstrategy \\
\hline
\end{tabular}




\begin{tabular}{|l|c|l|}
\hline \multicolumn{1}{|c|}{ Business Intelligence Tool } & $\begin{array}{c}\text { Most recent } \\
\text { version }\end{array}$ & \multicolumn{1}{c|}{ Supplier } \\
\hline IBM Cognos Series 10 & 10.1 & IBM \\
\hline QlikView & 11 & QlikTech \\
\hline Board Management IntelligenceToolkit & 7.1 & Board International \\
\hline BizzScore Suite & 7.3 & EFM Software \\
\hline WebFocus & 8 & Information Builders \\
\hline Oracle Hyperion System & 9 & Oracle \\
\hline SAP NetWeaver BI & 7.3 & SAP \\
\hline JasperSoft (open source) & 4.5 & JasperSoft \\
\hline Style Intelligence & 11 & InetSoft \\
\hline Pentaho BI suite (open source) & 4 & Pentaho \\
\hline Tableau Software & 6.1 & Tableau Software \\
\hline
\end{tabular}

(Source: http://businessintelligencetoolbox.com)

The list presented in Table 1 consists of 16 positions. In order to choose the best system, first, a few BI systems will be shortlisted, which will be analyzed in the next part of this work in detail.

Assumed criteria of selection (so called MUST-BEs) are fulfilled when the system:

- has a configurable management dashboard among its functionalities

- was successfully implemented in a public, state or education sector

- was successfully implemented in Poland

- offers possibility to integrate with various data sources.

On the basis of these criteria the list has been narrowed down to 4 positions:

- SAP Business Objects Enterprise XI

- Microsoft BI tools (integrated BI offering)

- Oracle Enterprise BI Server

- QlikView

\section{Comparative Analysis of Chosen BI Products}

The set of evaluation criteria for the comparative analysis have been created by 50 independent experts from the USA, UK, France and Germany. Their work has been sold to 2 consulting companies from the 'big five' and Passionned Group.

Comparative Analysis Method consists of the list of 200 evaluation criteria spread across 12 categories:

- Infrastructure \& architecture

- Security \& connectivity

- Cloud architecture

- Mobile Business Intelligence

- Core functionality 
- Performance management \& planning

- Predictive Analysis \& data mining

- Usability \& visualization

- Performance issues \& Big Data

- Search \& alerting

- Costs \& pricing

- General information

Depending on the organization and actual needs different categories or criteria can be selected for further analysis.

For the purposes of the SYNAT project, the customized set of criteria and the level of importance of the given criteria were developed by the author - Anna Maria Misiak, on the basis of the SYNAT projects characteristic. The complete list has been confirmed by prof. Jerzy Kisielnicki and sent to BI vendors: SAP, Microsoft, Hogart (distributor of QlickView in Poland) and Oracle, all based in Poland. In the next step there was a need to meet representatives (business specialists) of chosen vendors and go through all criteria again to make sure of the common understanding.

To carry out a comparison of the above BI products, criteria must be chosen specially for the SYNAT project with properly assigned importance. The criteria including the results are presented in Table 2, where:

Importance level: 1- very important, 2-important, 3 - important but not obligatory.

Respectively weights: $1=1,2=0.5,3=0.25$

Is the given criterion fulfilled by the product? $\mathrm{N}=$ no, $\mathrm{Y}=$ yes

Table 2. Classification criteria of BI products and their comparison.

Source: Own work

\begin{tabular}{|l|c|c|c|c|c|}
\hline \multicolumn{1}{|c|}{ Criterion } & $\begin{array}{l}\text { Importance } \\
\text { level (1,2,3) }\end{array}$ & SAP & MS & QlickView & Oracle \\
\hline Infrastructure and architecture & & & & & \\
\hline $\begin{array}{l}\text { Central installation on a server and a dashboard } \\
\text { available through the web browser }\end{array}$ & 1 & $\mathrm{Y}$ & $\mathrm{Y}$ & $\mathrm{Y}$ & $\mathrm{Y}$ \\
\hline $\begin{array}{l}\text { Integration with any operating system including } \\
\text { open-source }\end{array}$ & 1 & $\mathrm{Y}$ & $\mathrm{Y}$ & $\mathrm{Y}$ & $\mathrm{Y}$ \\
\hline $\begin{array}{l}\text { Administration: central management and support } \\
\text { of the system from the console }\end{array}$ & 2 & $\mathrm{Y}$ & $\mathrm{Y}$ & $\mathrm{Y}$ & $\mathrm{Y}$ \\
\hline $\begin{array}{l}\text { Administration: possibility to generate audit re- } \\
\text { ports (Audit Trail Report) }\end{array}$ & 2 & $\mathrm{Y}$ & $\mathrm{Y}$ & $\mathrm{Y}$ & $\mathrm{Y}$ \\
\hline $\begin{array}{l}\text { Administration: automatic function: Restart \& } \\
\text { Recovery }\end{array}$ & 2 & $\mathrm{Y}$ & $\mathrm{Y}$ & $\mathrm{Y}$ & $\mathrm{Y}$ \\
\hline $\begin{array}{l}\text { Administration: blocking and log-in function to } \\
\text { the system }\end{array}$ & 1 & $\mathrm{Y}$ & $\mathrm{Y}$ & $\mathrm{Y}$ & $\mathrm{Y}$ \\
\hline $\begin{array}{l}\text { Administration: build-in helpdesk or a possibility } \\
\text { to integrate with any helpdesk tool }\end{array}$ & 3 & $\mathrm{~N}$ & $\mathrm{Y}$ & $\mathrm{N}$ & $\mathrm{N}$ \\
\hline
\end{tabular}




\begin{tabular}{|c|c|c|c|c|c|}
\hline Criterion & $\begin{array}{l}\text { Importance } \\
\text { level }(1,2,3)\end{array}$ & SAP & MS & QlickView & Oracle \\
\hline $\begin{array}{l}\text { Access to user documentation / manual from the } \\
\text { system level }\end{array}$ & 3 & Y & $\mathrm{Y}$ & Y & $\mathrm{Y}$ \\
\hline $\begin{array}{l}\text { Integration with any external system including } \\
\text { data sources and other sources (e.g. external por- } \\
\text { tals) }\end{array}$ & 1 & Y & Y & $\mathrm{Y}$ & $\mathrm{Y}$ \\
\hline $\begin{array}{l}\text { Data extract in any file format including Excel and } \\
\text { PDF }\end{array}$ & 1 & Y & Y & $\mathrm{Y}$ & $\mathrm{Y}$ \\
\hline $\begin{array}{l}\text { Possibility to integrate with any e-mail system } \\
\text { (including the domain) }\end{array}$ & 1 & Y & Y & $\mathrm{Y}$ & $\mathrm{Y}$ \\
\hline $\begin{array}{l}\text { Efficiency of data warehouse: generating compre- } \\
\text { hensive reports within a maximum } 10 \text { seconds }\end{array}$ & 1 & Y & Y & $\mathrm{Y}$ & $\mathrm{Y}$ \\
\hline $\begin{array}{l}\text { Increase in efficiency of actions through addition- } \\
\text { al CPU and RAM actions on local servers }\end{array}$ & 1 & $\mathrm{~N}$ & Y & $\mathrm{N}$ & $\mathrm{Y}$ \\
\hline \multicolumn{6}{|l|}{ Security \& connectivity } \\
\hline Safe logging in (user, password) & 1 & Y & $\mathrm{Y}$ & $\mathrm{Y}$ & $\mathrm{Y}$ \\
\hline Possibility to give authorizations on the table level & 1 & Y & $\mathrm{Y}$ & $\mathrm{Y}$ & $\mathrm{Y}$ \\
\hline $\begin{array}{l}\text { Possibility to give authorizations on the column } \\
\text { level }\end{array}$ & 1 & $\mathrm{~N}$ & $\mathrm{Y}$ & $\mathrm{N}$ & $\mathrm{Y}$ \\
\hline Following history of changes (history file logs) & 1 & $\mathrm{Y}$ & $\mathrm{Y}$ & $\mathrm{Y}$ & $\mathrm{Y}$ \\
\hline \multicolumn{6}{|l|}{ Core functionality } \\
\hline Alert System & 1 & $\mathrm{Y}$ & $\mathrm{Y}$ & $\mathrm{Y}$ & $\mathrm{Y}$ \\
\hline $\begin{array}{l}\text { Functionality OLAP (On-Line Analytical Pro- } \\
\text { cessing) }\end{array}$ & 2 & Y & $\mathrm{N}$ & $\mathrm{Y}$ & $\mathrm{Y}$ \\
\hline Possibility to report AD-HOC & 1 & $\mathrm{Y}$ & $\mathrm{Y}$ & $\mathrm{Y}$ & $\mathrm{Y}$ \\
\hline Reporting PUSH and PULL & 2 & Y & $\mathrm{N}$ & $\mathrm{N}$ & $\mathrm{Y}$ \\
\hline 'Drill-down' functions & 1 & $\mathrm{Y}$ & $\mathrm{Y}$ & $\mathrm{Y}$ & $\mathrm{Y}$ \\
\hline Possibility to search data in text formats and files & 1 & $\mathrm{~N}$ & $\mathrm{Y}$ & $\mathrm{N}$ & $\mathrm{N}$ \\
\hline $\begin{array}{l}\text { Possibility to present data in any range including } \\
\text { historical data }\end{array}$ & 1 & $\mathrm{Y}$ & Y & Y & $\mathrm{Y}$ \\
\hline $\begin{array}{l}\text { Possibility to set own input parameters without the } \\
\text { need to know SQL or other request language }\end{array}$ & 1 & $\mathrm{~N}$ & Y & $\mathrm{N}$ & $\mathrm{N}$ \\
\hline $\begin{array}{l}\text { Possibility to make any aggregation of data, calcu- } \\
\text { lations etc. }\end{array}$ & 1 & Y & Y & $\mathrm{Y}$ & $\mathrm{Y}$ \\
\hline $\begin{array}{l}\text { Possibility to present data graphically e.g. in the } \\
\text { form of charts }\end{array}$ & 1 & Y & Y & Y & Y \\
\hline Possibility to format presentation elements & 2 & $\mathrm{Y}$ & Y & Y & $\mathrm{N}$ \\
\hline $\begin{array}{l}\text { Possibility to save templates of formatted reports / } \\
\text { dashboards }\end{array}$ & 2 & Y & $\mathrm{Y}$ & $Y$ & $Y$ \\
\hline
\end{tabular}




\begin{tabular}{|c|c|c|c|c|c|}
\hline Criterion & $\begin{array}{l}\text { Importance } \\
\text { level }(1,2,3)\end{array}$ & SAP & MS & QlickView & Oracle \\
\hline $\begin{array}{l}\text { Possibility to create own dashboards without a } \\
\text { need for programming (built-in function) }\end{array}$ & 1 & $\mathrm{~N}$ & $\mathrm{Y}$ & Y & $\mathrm{N}$ \\
\hline Interactive dashboards & 2 & $\mathrm{Y}$ & $\mathrm{Y}$ & $\mathrm{Y}$ & $\mathrm{Y}$ \\
\hline $\begin{array}{l}\text { Possibility to create and change KPIs on user / } \\
\text { group of users level without influencing globally } \\
\text { defined KPIs }\end{array}$ & 1 & Y & $\mathrm{Y}$ & $\mathrm{Y}$ & Y \\
\hline WHAT-IF analyses & 2 & $\mathrm{Y}$ & $\mathrm{N}$ & $\mathrm{Y}$ & $\mathrm{Y}$ \\
\hline Scheduling report generations functionality & 2 & $\mathrm{Y}$ & $\mathrm{Y}$ & $\mathrm{Y}$ & $\mathrm{Y}$ \\
\hline $\begin{array}{l}\text { Automatically sending generated dashboards by e- } \\
\text { mail }\end{array}$ & 1 & Y & $\mathrm{Y}$ & $\mathrm{Y}$ & Y \\
\hline $\begin{array}{l}\text { Servicing many localizations and creating dash- } \\
\text { boards depending on localization }\end{array}$ & 1 & Y & $\mathrm{Y}$ & Y & Y \\
\hline \multicolumn{6}{|l|}{ ETL functionality } \\
\hline ETL: Metadata central functions & 1 & $\mathrm{Y}$ & $\mathrm{Y}$ & Y & Y \\
\hline ETL: Transformation of any data formats & 1 & $\mathrm{Y}$ & $\mathrm{Y}$ & $\mathrm{Y}$ & $\mathrm{Y}$ \\
\hline ETL: Creating business rules & 1 & $\mathrm{Y}$ & $\mathrm{Y}$ & $\mathrm{Y}$ & $\mathrm{Y}$ \\
\hline ETL: Functions of data cleansing and aggregation & 1 & $\mathrm{Y}$ & $\mathrm{Y}$ & $\mathrm{Y}$ & $\mathrm{Y}$ \\
\hline ETL: Error management & 1 & Y & Y & $\mathrm{Y}$ & Y \\
\hline ETL: Scheduling ETL works & 1 & Y & Y & Y & Y \\
\hline Functions of managing data quality & 1 & $\mathrm{Y}$ & $\mathrm{Y}$ & $\mathrm{Y}$ & $\mathrm{Y}$ \\
\hline \multicolumn{6}{|l|}{$\begin{array}{l}\text { Additional functionality for Project Manage- } \\
\text { ment purposes }\end{array}$} \\
\hline $\begin{array}{l}\text { Functionality: planning (connections with the cal- } \\
\text { endar and alert system) }\end{array}$ & 1 & $\mathrm{~N}$ & $\mathrm{Y}$ & $\mathrm{N}$ & $\mathrm{N}$ \\
\hline Functionality: managing data resources & 1 & $\mathrm{~N}$ & $\mathrm{Y}$ & $\mathrm{N}$ & $\mathrm{N}$ \\
\hline $\begin{array}{l}\text { Functionality: managing other resources for pro- } \\
\text { ject organization needs }\end{array}$ & 1 & $\mathrm{~N}$ & Y & $\mathrm{N}$ & $\mathrm{N}$ \\
\hline $\begin{array}{l}\text { Functionality: work-flow, including approval hi- } \\
\text { erarchy }\end{array}$ & 1 & $\mathrm{~N}$ & Y & $\mathrm{N}$ & $\mathrm{N}$ \\
\hline Functionality: check-in \& check-out & 1 & $\mathrm{~N}$ & $\mathrm{Y}$ & $\mathrm{N}$ & $\mathrm{N}$ \\
\hline $\begin{array}{l}\text { Creating own tasks-tracking templates (tasks with- } \\
\text { in the plans) }\end{array}$ & 1 & $\mathrm{~N}$ & $\mathrm{Y}$ & $\mathrm{N}$ & $\mathrm{N}$ \\
\hline $\begin{array}{l}\text { System of managing access authorizations to indi- } \\
\text { vidual resources }\end{array}$ & 1 & $\mathrm{~N}$ & Y & $\mathrm{N}$ & $\mathrm{N}$ \\
\hline \multicolumn{6}{|l|}{ Additional criteria } \\
\hline $\begin{array}{l}\text { The tool has been used in project similar to } \\
\text { SYNAT }\end{array}$ & 1 & $\mathrm{~N}$ & Y & $\mathrm{N}$ & $\mathrm{N}$ \\
\hline $\begin{array}{l}\text { High availability of implementation consultants } \\
\text { in Polish market }\end{array}$ & 2 & Y & $\mathrm{Y}$ & $\mathrm{N}$ & $\mathrm{N}$ \\
\hline
\end{tabular}




\begin{tabular}{|l|c|c|c|c|c|}
\hline \multicolumn{1}{|c|}{ Criterion } & $\begin{array}{l}\text { Importance } \\
\text { level (1,2,3) }\end{array}$ & SAP & MS & QlickView & Oracle \\
\hline $\begin{array}{l}\text { The tool may be administered by internal re- } \\
\text { sources }\end{array}$ & 2 & $\mathrm{~N}$ & $\mathrm{Y}$ & $\mathrm{N}$ & $\mathrm{N}$ \\
\hline $\begin{array}{l}\text { Implementation of the tool lasting up to 6 months } \\
\text { (whole implementation cycle, including trainings } \\
\text { and organizational changes) }\end{array}$ & 1 & $\mathrm{~N}$ & $\mathrm{Y}$ & $\mathrm{Y}$ & $\mathrm{N}$ \\
\hline $\begin{array}{l}\text { Product integrity (i.e. if delivered product is one } \\
\text { integrated product or does it have a multi-module } \\
\text { construction which has an influence on the license } \\
\text { price) }\end{array}$ & 1 & $\mathrm{Y}$ & $\mathrm{N}$ & $\mathrm{Y}$ & $\mathrm{N}$ \\
\hline
\end{tabular}

Principles:

1. The criteria have been chosen considering the needs of the SYNAT project,

2. The level of importance of individual criteria has been assigned on the basis of knowledge of the SYNAT project and possible needs / requirements,

3. Product comparison $(\mathrm{Y}=\mathrm{yes}, \mathrm{N}=\mathrm{no})$ has been done on the basis of available materials from solution suppliers.

Results of the comparison have been calculated on the basis of the sum of the multiplication of fulfillment of the condition and the weight assigned to the importance of the criterion. Table 3 presents the results:

Table 3. Results of the comparison of the products. Source: Own work

\begin{tabular}{|c|l|}
\hline SAP & $27+(11 * 0.5)+(1 * 0.25)=32.75$ \\
\hline MS & $\mathbf{4 0}+(\mathbf{9} * \mathbf{0 . 5})+(\mathbf{2} * \mathbf{0 . 2 5})=\mathbf{4 5}$ \\
\hline QlickView & $32+(6 * 0.5)+(1 * 0.25)=35.25$ \\
\hline Oracle & $28+(9 * 0.5)+(1 * 0.25)=32.75$ \\
\hline
\end{tabular}

The results of the assessment of solutions are quite similar. Microsoft BI solution fulfills the highest number of the required criteria according to the simple analysis carried out.

All compared solutions are products that offer high class management dashboards, including cutting edge functionalities and attractive graphics. However, actual needs of the SYNAT project should be stressed here because they will be slightly different from the requirements typical for a commercial enterprise. These may include:

- Functionality or an additional module dedicated for Project Management. MS has such a product called SharePoint. It is a part of MS BI. It is simple in implementation and has high efficiency. In SYNAT's project conditions, where the management platform for project documents is not fully operating such a solution would seem to be perfect.

- The possibility to integrate with the system storing project documents. As mentioned above there is integration with SharePoint. MS offers integration with other systems dedicated to storing documents including file servers. Thanks to the search functionality for text files, in MS dashboards KPIs characteristic for project management may be configured. 
- Using the product in other similar operations. MS BI, including SharePoint, is a product which is often used for project management. Simplicity of implementation of ETL Layer, data warehouses and dashboards and therefore common knowledge of MS products makes participants of the project willing to use this solution.

- Swiftness of implementation and product scalability. The SYNAT project has its deadline. Therefore, a long-term implementation of a tool cannot be allowed. In the case of implementation of the management dashboard the implementation process mainly involves implementation of other layers of Business Intelligence as well. It is usually a long process requiring significant interactivity on the customer's side. MS solutions will also require customer's participation. However, due to the common usage of MS products, time frames of some implementation phases - e.g. configuration of the solution, tests and trainings will be shorter compared with SAP or Oracle solutions.

- Using the tool after the finishing of the SYNAT project. Doubtlessly SYNAT will evolve and develop after the official GO-Live. Therefore, BI should include flexible functionality and the possibility of quick re-parameterization of each its layer. Such possibilities are also offered by the tools considered in the analyses. MS is the tool which can be easily reconfigured by local administrators without a need for external consultants. All MS tools assume implementation options through internal resources. It is an important element which should be considered while choosing BI product.

The analysis carried out suggests using Microsoft solutions which are based on Microsoft BI tools. Therefore, for the purpose of furthering this dissertation the analysis of BI tool use will be based on Microsoft BI tools.

\section{Expenditures and effects of using $\mathrm{BI}$}

The implementation of $\mathrm{BI}$ is connected with some necessary investments.

Preparing a detailed cost calculation for the implementation of the MS BI solution requires knowledge of the number of participants in the project and currently existing technical and application infrastructure. For the needs of this dissertation some assumptions were made in order to estimate the budget required to implement the proposed solution.

Assumptions:

1. Number of users depending on the size of the project:

\begin{tabular}{|c|c|c|c|c|}
\hline $\begin{array}{c}\text { Size of the } \\
\text { organization }\end{array}$ & $\begin{array}{c}\text { Number of users of } \\
\text { BI and SharePoint }\end{array}$ & $\begin{array}{c}\text { BI Report Crea- } \\
\text { tors }\end{array}$ & $\begin{array}{c}\text { Installation and } \\
\text { parameterization } \\
\text { (Days) }\end{array}$ & Comments \\
\hline Small & 25 & 5 & 30 & \\
\hline Medium & 100 & 20 & 100 & \\
\hline Large & 500 & 100 & $\mathbf{6 0}$ & $\begin{array}{c}\text { There is app. 1-2 BI } \\
\text { Creators per institution } \\
\text { participating in SYNAT }\end{array}$ \\
\hline Optimal for & $\mathbf{2 0 0}$ & $\mathbf{5 0}$ & & \\
\hline
\end{tabular}

2. Required purchase of a server and server licenses; 
3. Users currently have MS 2010 Office standard installed on their computers;

4. 1 day of work for a Microsoft implementation specialist costs PLN 2000 (on the basis of data from Microsoft and IBM in Poland);

5. Internal costs connected with participation of SYNAT users / coordinators in workshops and meetings in order to define needs of MS BI are not included in the cost calculations;

6. Assumed exchange rate in order to recalculate the Microsoft pricelists: 1 USD $=3$ PLN.

The presented estimated cost in the Appendix assumes the least favorable conditions such as a lack of IT infrastructure and discounts for MS licenses. These costs may be lowered by $20-30 \%$ with more precise evaluation of needs, current computer architecture and negotiations.

Additionally, there are so called hidden costs, which are hard to convert directly into monetary terms. One of them is motivation of users to use the BI system as effectively as possible. It is a difficult and sometimes long process. An interesting 'soft' approach which has been recently used by organizations is to make it 'fashionable' to use the newly implemented technology. Such an approach originated within consumer electronics company Apple Inc. due to the initiative of Steve Jobs. Its idea was creating a fashion for the 'product'. It has a very positive result on the market which is filled up with modern technology. This idea was taken and modified for the internal needs of the organization. Perhaps such technique will be successful in the SYNAT project.

\section{Effect of using BI}

The goal of the SYNAT project is to build a publicly available e-platform for dissemination of scientific knowledge, operating on the basis of the Open Access principle. It indicates the reach of this project and number of scientific, commercial and other institutions engaged in this project. Using BI while building this platform should bring at least such effects as:

- Integration of many computer platforms with locally prepared plans and products of the project;

- Better coordination of the decentralized structure of the project mainly taking into consideration:

- Budget

- Resources i.e. legal decisions, rules of participation and funding participants of the project

- Products of the project - their actual value for the project

- Timeliness of delivering products and tasks

- Risk, threats and ease of escalation

- Virtualization of common work which may have direct influence on lowering the travelling costs

- Swiftness of receiving the Status Quo about the project thanks to the management dashboards

\section{Final Remarks}

Scientific and technical information is the intellectual and strategic capital of each country. Therefore, each country designs proper financial and personal resources depending on the availa- 
ble resources of the country. The existing and developed national systems should be connected with global network of all platforms disseminating such resources of knowledge. In this regard it is important to work to improve existing integration tools and create an inter-operational platform. The European Council has already expressed its opinion in this issue and this position is shared by the most important international organizations.

Regardless of this, activities should be carried out to promote the rules of using Open Access, which is a good direction both to provide national systems with so called contess as well as promoting valuable works created in less well known scientific institutions.

It is recommended to use BI tools and a management dashboard to manage such complex project as national systems for disseminating knowledge. The analysis carried out shows that such solutions are effective and do not require relatively high expenses. Due to the importance of the issue in Poland works on SYNAT will be continued especially regarding developing the system and connecting it to such systems in other countries.

\section{References}

Adamick, J. (2010). Trends in large-scale subject repositories. In D-Lib Magazine,16(11/12). Retrieved from http://www.dlib.org/dlib/november10/11 contents.html

Arlt, Ch. (2006). Digital Right Management Systeme. Der Einsatz technischer Maßnahmen zur Schutz der digitalen Inhalte. C.H. Beck. München.

Björk, B., Roos, A., \& Lauri, M. (2009). Scientific journal publishing: Yearly volume and open access availability. Information Research, 14(1), March. Retrieved from http://informationr.net/ir/141/paper391.html

Castells, M. (1996). The rise of the network society. Blackwell Publishers. Oxford.

Crow, R. (2008). The case for institutional repositories: A SPARC position paper. Washington DC. Retrieved from http://www.arl.org/sparc/IR/ir.html

Dutta, S., \& Mia, I. (2012). The global information technology report 2010-2011: Transformations 2.0. INSEAD Country/ Rank within Economy Rank Score income group. Retrieved from http://www3.weforum.org/docs/WEF_GITR_Report_2011.pdf

Gibbons, S. (2004). Establishing an institutional repository. Library Technology Reports, 40(4), 1-168. Retrieved from https://publications.techsource.ala.org/products/archive.pl?article=2538

Hollender, H. (Ed.). (2011). Sprawozdanie z I etapu realizacji SYNAT. [Report from the first chase of the SYNAT Project] Uczelnia Łazarskiego. Warszawa.

Houghton, J., Rasmussen, B., Sheehan, S.; Oppenheim, C., Morris, A., Creaser, C., ... Gourlay, A. (2009). Economic implications of alternative scholarly publishing models: Exploring the costs and benefits. JISC EI-ASPM Project. Report to the Joint Information Systems Committee (JISC) (UK). CSES and Loughborough University. January

Houghton, J., \& Strategic Networks Group. (2008). Australian digital economy benchmarking. Report to the Department of Broadband, Communications and the Digital Economy by Strategic Network

Olszak C., \& Ziemba E. (2007). Strategie i modele gospodarki elektronicznej. Chapter 11: Systemy Business Intelligance.

Passionned Group. (2012). Business intelligence tools survey 2012. Retrieved from http://businessintelligencetoolbox.com

Rawicz-Mańkowski. (2008) G. Business intelligence - skad przyszedl, dokad zmierza?. Retrieved from http://bi.pl/publications/art/10-business-intelligence-skad-przyszedl-dokad-zmierza 
Sabherwal, R., \& Becerra-Fernandez, I. (2011). Business intelligence, practices, technologies, and management.

Surma J. (2009). Business intelligence. Wydwanictwo Naukowe PWN

Warren, N., Neto, M. T., Campbell, J., \& Misner, S. (2011). Business intelligence in Microsoft SharePoint 2010. Microsoft Press

\section{Appendix}

Estimated cost of implementation of the proposed MS BI solution

\begin{tabular}{|c|c|c|c|c|}
\hline Implementation & Small & Medium & Large & Optimal \\
\hline Implementation Cost & Total & Total & Total & Total \\
\hline \multirow{2}{*}{ Assumed number of consulting days (man-days) } & PLN $60,000.00$ & PLN 70,000.00 & PLN 200,000.00 & PLN $120,000.00$ \\
\hline & PLN 60,000.00 & PLN 70,000.00 & PLN 200,000.00 & PLN $120,000.00$ \\
\hline \multicolumn{5}{|l|}{ Hardware } \\
\hline \multirow{3}{*}{$\begin{array}{l}\text { Serwer } \\
\text { PowerEdge M710HD Blade Server DELL }\end{array}$} & Total & Total & Total & Total \\
\hline & PLN $30,000.00$ & PLN 30,000.00 & PLN 30,000.00 & PLN 30,000.00 \\
\hline & PLN 30,000.00 & PLN 30,000.00 & PLN $30,000.00$ & PLN 30,000.00 \\
\hline \multicolumn{5}{|l|}{ Licenses (Client Components) } \\
\hline Licenses & Total & Total & Total & Total \\
\hline Office 2010 Professional Plus: For people who create reports & PLN 7,620.00 & PLN 30,480.00 & PLN $152,400.00$ & PLN 76,200.00 \\
\hline Office 2010 Standard: Reports readers & PLN 0.00 & PLN 0.00 & PLN 0.00 & PLN 0.00 \\
\hline SharePoint Standard CALs for collaborators & PLN 6,225.00 & PLN 24,900.00 & PLN $124,500.00$ & PLN 49,800.00 \\
\hline SharePoint Enterprise CALs for collaborators & PLN 7,125.00 & PLN 28,500.00 & PLN $142,500.00$ & PLN $57,000.00$ \\
\hline Total & PLN 20,970.00 & PLN 83,880.00 & PLN 419,400.00 & PLN 183,000.00 \\
\hline \multicolumn{5}{|l|}{ Required server licenses } \\
\hline Licenses & Total & Total & Total & Total \\
\hline Windows Server 2008 R2 Data Center Edition licenses & PLN 0.00 & PLN 0.00 & PLN 0.00 & PLN 0.00 \\
\hline Windows Server 2008 R2 Enterprise Edition licenses & PLN 21,222.00 & PLN 21,222.00 & PLN 21,222.00 & PLN 21,222.00 \\
\hline SQL Server 2008 R2 Data Center Edition licenses & PLN 0.00 & PLN 0.00 & PLN 0.00 & PLN 0.00 \\
\hline SQL Server 2008 R2 Enterprise Edition licenses & PLN $247,455.00$ & PLN 247,455.00 & PLN 247,455.00 & PLN 247,455.00 \\
\hline SharePoint Server 2010 licenses & PLN $14,778.00$ & PLN $14,778.00$ & PLN 14,778.00 & PLN $14,778.00$ \\
\hline Total & PLN 283,455.00 & PLN 283,455.00 & PLN $283,455.00$ & PLN 283,455.00 \\
\hline \multicolumn{5}{|l|}{ Additional Cost } \\
\hline Additional Cost (Travels etc.) & Total & Total & Total & Total \\
\hline \multirow[t]{2}{*}{ Assumed extra cost $=15 \%$ of the total above cost } & PLN 59,163.75 & PLN 68,600.25 & PLN 139,928.25 & PLN 92,468.25 \\
\hline & PLN 59,163.75 & PLN 68,600.25 & PLN 139,928.25 & PLN 92,468.25 \\
\hline Estimated TOTAL Implementation Cost & PLN 453,588.75 & PLN 525,935.25 & PLN 1,072,783.25 & PLN 708,923.25 \\
\hline
\end{tabular}

Estimated cost of implementation of the proposed MS BI solution, Source: Own works 


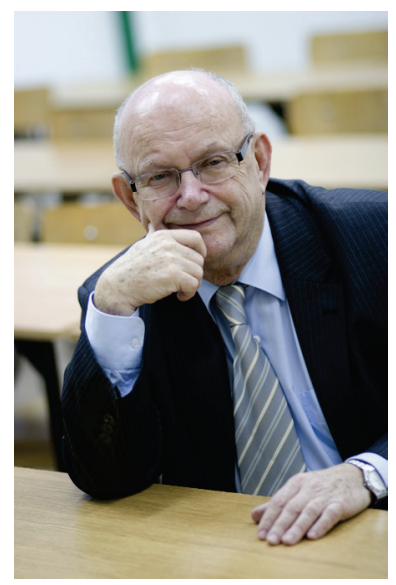

\section{Biographies}

Jerzy Kisielnicki professor of management has been the head of the Department of Information Systems in Management and Faculty of Management at Warsaw University He has been the head of the Department of Management at Marketing at the Lazarski University.

His interests are organization and management, systems analysis, management information systems, e-learning, process innovation (reengineering), strategic management, and transition systems organization and management in market economy. Dr. Kisielnicki is a member of the Board of Organization and Management in Polish Academy of Science and is the head of the Scientific Council of Polish Society of Systems Information. He has had about 220 publications.

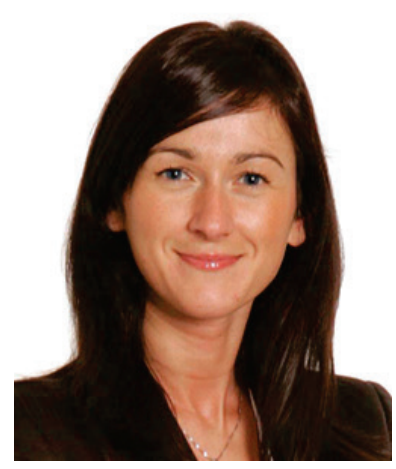

Anna Maria Misiak PhD student at the University of Technology, Department of Information Systems in Management. Her current area of research is focusing on factors impacting the process of preparing organizations to Business Intelligence implementation.

Her research interests include organization transformations, reengineering processes, system analysis, implementation of management systems and project management. She is working as an independent consultant responsible for business applications' integration. She has been involved in many projects of mergers and acquisitions. This experience is the research base to her publications and the $\mathrm{PhD}$ Thesis. 